\section{Pessoas com deficiência na pandemia da COVID-19: garantia de direitos fundamentais e equidade no cuidado}

\author{
Persons with disabilities during the COVID-19 \\ pandemic: guaranteeing fundamental rights and \\ equity in care
}

\section{Personas con discapacidad en la pandemia de COVID-19: garantía de derechos fundamentales y equidad en el cuidado}

Ana Paula Medeiros Pereira 1

Amanda Oliveira Costa dos Santos 2

Beatriz Santos Miranda 2

Hercília Kayla Santos de Carvalho 2

Lilia Campos Nascimento 1

Mariana Santos Amaral 2

Mariana Silva Macedo 2

Melissa Catrini 2

Milena Maria Cordeiro de Almeida 2
Jorge Henrique Santos Saldanha 1,2

\section{Resumo}

Este trabalho é uma revisão de escopo realizada nas bases de dados PubMed, Scopus, BIREME, SciELO e Web of Science, que incluiu publicações de dezembro de 2019 a maio de 2020, com o objetivo de identificar e sistematizar a literatura sobre a situação das pessoas com deficiência nos primeiros meses da pandemia da COVID-19. A revisão foi orientada para a busca de artigos originais, publicados em revistas indexadas e revisados por pares, além de literatura cinzenta especializada. Foram revisados 386 textos e incluídos no estudo 33 artigos e documentos. O resultado da revisão apontou três categorias temáticas que refletem as principais discussões apresentadas na literatura sobre o tema: vulnerabilidades das pessoas com deficiência diante da pandemia; direitos das pessoas com deficiência nesse contexto; e medidas de proteção e acesso à informação sobre COVID-19 voltadas para pessoas com deficiência. No contexto de emergência em saúde pública, comunidades historicamente marginalizadas, como as pessoas com deficiência, correm o risco de se sentirem mais vulneráveis, bem como sofrerem privações e discriminação nos planos de triagem de atendimento, além de preconceitos e estigmas que influenciam nas tomadas de decisão na assistência em saúde e intensificam desigualdades preexistentes, tornando esse grupo mais suscetivel ao adoecimento e à desproteção social. Embora as pessoas com deficiência tenham sido reconhecidas como grupo de risco para COVID-19, houve um atraso, por parte dos governos, na construção de planos de enfrentamento à doença para essa população. São escassos estudos para a compreensão dos efeitos da pandemia da COVID-19 nas pessoas com deficiência, especialmente no sentido da efetivação de medidas de prevenção, controle e proteção que garantam a equidade no cuidado.

Pessoas com Deficiência; Infecções por Coronavírus; COVID-19
Correspondência

J. H. S. Saldanha

Departamento de Fisioterapia, Instituto de Ciências da Saúde, Universidade Federal da Bahia.

Av. Reitor Miguel Calmon s/n, Salvador, BA 40110-100, Brasil. jhsaldanha@gmail.com

1 Instituto de Saúde Coletiva, Universidade Federal da Bahia, Salvador, Brasil.

2 Instituto de Ciências da Saúde, Universidade Federal da Bahia, Salvador, Brasil. 


\section{Introdução}

A pandemia da COVID-19 intensificou desafios relacionados à atenção em saúde e proteção social das pessoas com deficiência. Estima-se que as pessoas com deficiência representem cerca de 1 bilhão de pessoas (15\% da população mundial) 1 , que já vivenciavam invisibilização e confinamento ao longo do tempo, além de uma rotina de necessidades de cuidado em saúde, e tiveram sua vulnerabilidade social aumentada durante a pandemia. Por isso, a Organização Mundial da Saúde (OMS) reconheceu as pessoas com deficiência como grupo de risco para COVID-19, apontando recomendações de ações específicas de prevenção, controle, assistência e proteção social para governos, profissionais de saúde, comunidades e familiares 2 .

Ter alguma deficiência aumenta a probabilidade de maior custo de vida e desemprego, e menor escolaridade, além de dificultar o acesso à saúde, levando essas pessoas a vivenciarem mais situações de pobreza 3. Mesmo assim, a garantia de direitos à pessoas com deficiência faz parte de um passado recente, com início no mundo na década de 1960, resultado de movimentos sociais fortes em defesa dos direitos humanos, dignidade, autonomia e equiparação de oportunidades 4 . Também nessa década, sob a perspectiva das ciências sociais, a partir do chamado modelo social, fortalece-se uma abordagem sociopolítica da deficiência, como produto do desenvolvimento das sociedades contemporâneas, resultante de fatores socioambientais, como violência urbana, envelhecimento populacional, acidentes de trabalho, dentre outros 5 .

Desde então, o modelo social, sem ignorar os avanços biomédicos e as necessidades de pessoas com impedimentos corporais, tem sido proeminente no campo de estudos sobre a deficiência. A proposta do modelo é que a deficiência seja compreendida como um conceito amplo e relacional, como toda e qualquer forma de desvantagem resultante da relação do corpo com lesões e a sociedade ${ }^{6}$. Por isso, em um contexto social e ambiental diverso, como o de uma pandemia, as pessoas com deficiência, além de vivenciarem o aumento da morbimortalidade pela presença de comorbidades, tendem a ter o acesso a políticas públicas prejudicado, incluindo direitos essenciais como saúde, educação, transporte e assistência social, o que é somado às consequências físicas e sociais do aumento do isolamento social. O contexto da pandemia exacerba iniquidades sociais e de saúde, especialmente em países de média e baixa renda, com menor capacidade de resposta à pandemia, onde residem $80 \%$ das pessoas com deficiência 7 .

O Brasil é um desses países de menor renda, onde quase 46 milhões de pessoas, cerca de $24 \%$ da população (Instituto Brasileiro de Geografia e Estatística. https://sidra.ibge.gov.br/home/pnadcm, acessado em 18/Ago/2020), declarou ter algum tipo de deficiência, e tende a vivenciar de modo desproporcional a pandemia. Na atualização do Censo Demográfico de 2010, que buscou uniformizar os dados brasileiros com os internacionais a partir das recomendações do Grupo de Washington, quase 13 milhões de brasileiros, cerca de 6,7\% da população, apresentou algum tipo de deficiência 8 .

Embora a circulação do novo coronavírus (SARS-CoV-2) esteja acontecendo desde dezembro de 2019 e a pandemia tenha sido declarada pela OMS em 11 de março de $2020^{9}$, pouco se sabe sobre os efeitos desta nas pessoas com deficiência, no Brasil e no mundo. Poucos documentos institucionais foram publicados internacionalmente, como as recomendações da OMS 2, e nacionalmente, a exemplo de orientações em formato de cartilha do Ministério da Mulher, da Família e dos Direitos Humanos 10, apontando para uma lacuna de publicações sobre a temática. Portanto, o objetivo do presente estudo foi identificar e sistematizar a literatura sobre a situação das pessoas com deficiência nos primeiros meses da pandemia da COVID-19.

\section{Método}

Trata-se de uma revisão de escopo 11,12,13 sobre a situação das pessoas com deficiência nos primeiros meses da pandemia da COVID-19, incluindo condições de vida e saúde das pessoas com deficiência e respostas governamentais e institucionais para a garantia de direitos e cuidado em saúde. 


\section{Estratégia de pesquisa e fontes de dados}

Uma busca sistemática foi realizada nas bases de dados PubMed, Scopus, BIREME, SciELO, Web of Science, no período de abril a maio de 2020. A string de pesquisa utilizada na busca em todas as bases de dados foi: "coronavirus infections" OR "COVID-19" OR "SARS-CoV-2" AND "disability" OR "handicapped" OR "disabled persons". Busca manual e listas cruzadas de referência dos principais artigos também foram adicionadas.

A revisão foi orientada para identificar artigos originais, publicados em revistas indexadas e revisados por pares, além de literatura cinzenta especializada (manuais de orientação e resoluções de órgãos oficiais nacionais; textos de opinião e orientação de organizações de pessoas com deficiência nacionais ou internacionais) publicados entre dezembro de 2019 e maio de 2020.

\section{Critérios de inclusão e exclusão}

Foram selecionados para essa revisão estudos e documentos que abordassem a situação das pessoas com deficiência no contexto da pandemia da COVID-19; publicados entre dezembro de 2019 e maio de 2020; que tivessem foco central em populações com deficiência; nos idiomas inglês, português e espanhol. Foram excluídas revisões da literatura e estudos clínicos, além de estudos nos quais a incapacidade e/ou deficiência fosse abordada apenas como variável de desfecho da COVID-19.

\section{Seleção e inclusão de artigos e documentos}

Após excluídos os trabalhos duplicados, cada artigo foi analisado por uma dupla de pesquisadoras/ es que, separadamente, aplicou os critérios de inclusão e exclusão a partir da leitura do título e resumo. Os artigos foram selecionados a partir do consenso entre as/os avaliadoras/es e, nos casos de divergência, uma/um terceira/o avaliador/a foi incluída/o para opinar sobre a inclusão ou exclusão do estudo. Os textos da literatura cinzenta, selecionados através de busca manual, também foram submetidos a avaliação independente por duas/dois pesquisadoras/es para decidir sobre a inclusão.

\section{Análise dos estudos incluídos}

Informações gerais e metodológicas foram extraídas dos textos incluídos para a revisão e encontram-se detalhados nos Quadros 1 e 2. Dado o tipo de material encontrado na revisão, os estudos e documentos incluídos foram sintetizados a partir do método da síntese temática de Thomas \& Harden ${ }^{14}$. Códigos livres de descobertas foram organizados em temas "descritivos" e, posteriormente, interpretados para produzir as categorias analíticas apresentadas neste estudo.

\section{Resultados}

A busca nas bases de dados selecionou 370 artigos e a busca na literatura cinzenta reportou 34 textos potencialmente elegíveis para essa revisão. A Figura 1 sintetiza o processo de identificação, seleção, elegibilidade e inclusão dos artigos e documentos para a síntese da literatura. Após a recuperação de todos os textos potencialmente relevantes nas bases de dados e a busca manual, removemos as duplicatas e, em seguida, procedemos à fase de seleção com a leitura de títulos e resumos em confronto com os critérios de inclusão e exclusão. Após seleção inicial, todos os textos elegíveis foram lidos na íntegra para análise e seleção pelas/os pesquisadoras/es. Foram incluídos 33 artigos e documentos nesta revisão.

Os Quadros 1 e 2 sintetizam os artigos. Das 15 publicações científicas, a maioria era composta por editoriais 7,15,16,17,18 e artigos de opinião 19,20,21,22,23,24, e os demais observacionais 25,26, tópico atual 27 ou ensaio 28. Em relação aos países ou regiões dessas publicações, destacam-se os Estados Unidos e o Reino Unido (Quadro 1). Dentre os documentos da literatura cinzenta selecionados, a maioria foi composta por documentos institucionais 2,3,29,30,31,32,33,34,35 e artigos de opinião 36,37,38, sendo os demais entrevistas/reportagens 3,39 , editoriais 40 e protocolos ou outros documentos técni- 


\section{Quadro 1}

Descrição dos artigos selecionados e síntese dos resultados.

\begin{tabular}{|c|c|c|c|c|}
\hline Estudo (Ano) & País & Tipo & Objetivo & Principais achados \\
\hline Safta-Zecheria 17 (2020) & Romênia & Editorial & $\begin{array}{l}\text { Discutir o risco potencial } \\
\text { para a saúde das pessoas } \\
\text { com deficiência em } \\
\text { instituições de cuidados } \\
\text { residenciais durante o } \\
\text { surto da COVID-19. }\end{array}$ & $\begin{array}{l}\text { Alto risco de contágio exige políticas públicas e } \\
\text { ações governamentais para garantia de medidas } \\
\text { de proteção e cuidado à pessoas com deficiência: } \\
\text { financiamento, apoio a familiares/cuidadores e } \\
\text { manutenção da assistência. }\end{array}$ \\
\hline $\begin{array}{l}\text { Organização Pan-Americana } \\
\text { da Saúde } 15 \text { (2020) }\end{array}$ & $\begin{array}{l}\text { Estados } \\
\text { Unidos }\end{array}$ & Editorial & $\begin{array}{l}\text { Apontar medidas } \\
\text { adicionais para as } \\
\text { pessoas com deficiência } \\
\text { para mitigar os impactos } \\
\text { da COVID-19 nessa } \\
\text { população. }\end{array}$ & $\begin{array}{l}\text { Ações governamentais de proteção específicas } \\
\text { como manutenção do cuidado, ações de apoio a } \\
\text { familiares, cuidadores e comunidade a partir de } \\
\text { medidas de prevenção e controle da infecção. }\end{array}$ \\
\hline Jalali et al. 23 (2020) & Irã & $\begin{array}{l}\text { Artigo de } \\
\text { opinião }\end{array}$ & $\begin{array}{l}\text { Apresentar os desafios } \\
\text { que as pessoas com } \\
\text { deficiência enfrentam } \\
\text { durante a emergência da } \\
\text { COVID-19 no Irã. }\end{array}$ & $\begin{array}{l}\text { Interrupção do cuidado especializado, } \\
\text { dificuldades para subsistência, precário acesso } \\
\text { aos serviços de saúde e à informação, medidas } \\
\text { rígidas de isolamento são desafios impostos às } \\
\text { pessoas com deficiência. }\end{array}$ \\
\hline Courtenay 18 (2020) & $\begin{array}{l}\text { Reino } \\
\text { Unido }\end{array}$ & Editorial & $\begin{array}{l}\text { Apresentar os desafios } \\
\text { das pessoas com } \\
\text { deficiência intelectual do } \\
\text { Reino Unido diante da } \\
\text { pandemia da COVID-19. }\end{array}$ & $\begin{array}{c}\text { A manutenção da assistência demanda } \\
\text { adaptações e a colaboração entre os prestadores } \\
\text { de serviço e a família para redução do risco } \\
\text { de infecção e dos impactos das mudanças } \\
\text { estruturais nos serviços. }\end{array}$ \\
\hline Bettger et al. 24 (2020) & $\begin{array}{l}\text { Estados } \\
\text { Unidos }\end{array}$ & $\begin{array}{l}\text { Artigo de } \\
\text { opinião }\end{array}$ & $\begin{array}{l}\text { Descrever ajustes para } \\
\text { a continuidade dos } \\
\text { serviços de reabilitação } \\
\text { no contexto das } \\
\text { respostas nacionais } \\
\text { de enfrentamento da } \\
\text { COVID-19. }\end{array}$ & $\begin{array}{l}\text { Ações para garantir segurança dos trabalhadores, } \\
\text { implementação de serviços para manutenção do } \\
\text { cuidado como a telerreabilitação, capacitação da } \\
\text { equipe para orientar pacientes e familiares no } \\
\text { cuidado domiciliar e medidas de monitoramento } \\
\text { dos pacientes em recuperação pós-COVID-19. }\end{array}$ \\
\hline Vieira et al. 22 (2020) & Suíça & $\begin{array}{l}\text { Artigo de } \\
\text { opinião }\end{array}$ & $\begin{array}{l}\text { Explorar o impacto da } \\
\text { COVID-19 e suas medidas } \\
\text { de prevenção no bem- } \\
\text {-estar de populações } \\
\quad \text { vulneráveis. }\end{array}$ & $\begin{array}{l}\text { Barreiras no acesso aos serviços de saúde } \\
\text { exigem medidas de prevenção que incluem } \\
\text { informação veiculada de forma simples e } \\
\text { acessível. Deve-se incentivar oferta de serviços de } \\
\text { saúde mental por telessaúde. }\end{array}$ \\
\hline Pineda \& Corbuan 20 (2020) & $\begin{array}{l}\text { Estados } \\
\text { Unidos }\end{array}$ & $\begin{array}{l}\text { Artigo de } \\
\text { opinião }\end{array}$ & $\begin{array}{l}\text { Debater os impactos da } \\
\text { pandemia atual para } \\
\text { pessoas com deficiência } \\
\text { a partir dos princípios de } \\
\text { equidade urbana e teoria } \\
\text { social da deficiência. }\end{array}$ & $\begin{array}{l}\text { Cidades equânimes podem modificar o estado de } \\
\text { vulnerabilidade a partir de ações elaboradas com } \\
\text { a participação de pessoas com deficiência, que } \\
\text { garantam acessibilidade na informação e meios } \\
\text { de veiculação, suporte financeiro e manutenção } \\
\text { do cuidado. }\end{array}$ \\
\hline Mukherjee 19 (2020) & $\begin{array}{l}\text { Estados } \\
\text { Unidos }\end{array}$ & $\begin{array}{l}\text { Artigo de } \\
\text { opinião }\end{array}$ & $\begin{array}{c}\text { Refletir sobre } \\
\text { marcadores de } \\
\text { vulnerabilidade em } \\
\text { contextos de pandemia } \\
\text { relacionados a } \\
\text { deficiência, raça e etnia. }\end{array}$ & $\begin{array}{l}\text { A recusa de tratamento tem sido comum. O } \\
\text { preconceito pode influenciar a discriminação } \\
\text { nos planos de triagem e decisões da assistência. } \\
\text { A judicialização tem sido frequente. É preciso } \\
\text { fiscalização e busca de garantia dos direitos da } \\
\text { pessoas com deficiência. }\end{array}$ \\
\hline
\end{tabular}

(continua) 
Quadro 1 (continuação)

\begin{tabular}{|c|c|c|c|c|}
\hline Estudo (Ano) & País & Tipo & Objetivo & Principais achados \\
\hline Qi \& Hu 27 (2020) & $\begin{array}{l}\text { Reino } \\
\text { Unido }\end{array}$ & $\begin{array}{l}\text { Tópicos atuais } \\
\text { (current issue) }\end{array}$ & $\begin{array}{l}\text { Analisar a Lei sobre a } \\
\text { Prevenção e Tratamento } \\
\text { de Doenças Infecciosas } \\
\text { (LPTID) em meio à } \\
\text { pandemia da COVID-19. }\end{array}$ & $\begin{array}{c}\text { A LPTID não contempla necessidades específicas } \\
\text { de pessoas com deficiência, o que impõe } \\
\text { dificuldades e barreiras para medidas de } \\
\text { proteção e cuidado exigidas pela pandemia da } \\
\text { COVID-19. A perspectiva da deficiência deve } \\
\text { ser incluída na construção das leis, políticas e } \\
\text { práticas. }\end{array}$ \\
\hline Shew 21 (2020) & $\begin{array}{l}\text { Estados } \\
\text { Unidos }\end{array}$ & $\begin{array}{l}\text { Artigo de } \\
\text { opinião }\end{array}$ & $\begin{array}{l}\text { Apresentar as } \\
\text { contribuições da pessoas } \\
\text { com deficiência para } \\
\text { o enfrentamento da } \\
\text { pandemia da COVID-19. }\end{array}$ & $\begin{array}{c}\text { Tecnologias, adaptação dos espaços e tempo de } \\
\text { trabalho e soluções de infraestrutura criadas por } \\
\text { pessoas com deficiência têm sido utilizadas como } \\
\text { base para as adequações no funcionamento } \\
\text { de diversos serviços durante a pandemia da } \\
\text { COVID-19. }\end{array}$ \\
\hline $\begin{array}{l}\text { Yarımkaya \& Esentürk } 28 \\
(2020)\end{array}$ & Turquia & Ensaio & $\begin{array}{l}\text { Descrever os benefícios } \\
\text { da atividade física em } \\
\text { crianças com transtorno } \\
\text { do espectro autista (TEA) } \\
\text { e apresentar estratégias } \\
\text { durante a pandemia da } \\
\text { COVID-19. }\end{array}$ & $\begin{array}{c}\text { Realizar exercício de alta intensidade por pelo } \\
\text { menos } 20 \text { minutos ou de intensidade moderada } \\
\text { por } 30 \text { minutos todos os dias, num espaço amplo } \\
\text { e com a participação da família, tem efeitos } \\
\text { positivos sobre a saúde e qualidade de vida de } \\
\text { crianças com TEA e familiares em isolamento } \\
\text { social. }\end{array}$ \\
\hline Armitage \& Nellums 7 (2020) & $\begin{array}{l}\text { Reino } \\
\text { Unido }\end{array}$ & Editorial & $\begin{array}{l}\text { Discutir o impacto } \\
\text { da COVID-19 sobre a } \\
\text { prestação de cuidado de } \\
\text { saúde para a pessoas } \\
\text { com deficiência. }\end{array}$ & $\begin{array}{c}\text { Melhorar a prestação de cuidados de saúde } \\
\text { para esse grupo a partir da conscientização } \\
\text { sobre os direitos e necessidades da pessoas com } \\
\text { deficiência, garantia de continuidade do cuidado } \\
\text { com segurança para trabalhadores e familiares, } \\
\text { e acesso a emprego e educação. Deve-se incluir } \\
\text { pessoas com deficiência na elaboração de } \\
\text { estratégias e ações. }\end{array}$ \\
\hline Schiariti $16(2020)$ & Canadá & Editorial & $\begin{array}{l}\text { Apresentar os desafios } \\
\text { enfrentados por pessoas } \\
\text { com deficiência na } \\
\text { pandemia da COVID-19. }\end{array}$ & $\begin{array}{c}\text { Durante esse período, deve-se adotar uma } \\
\text { abordagem inclusiva baseada em direitos e } \\
\text { garantir que pessoas com deficiência participem } \\
\text { da concepção e implementação dos planos para } \\
\text { emergências. }\end{array}$ \\
\hline Negrini et al. 25 (2020) & Itália & $\begin{array}{c}\text { Observacional } \\
\text { transversal }\end{array}$ & $\begin{array}{l}\text { Fornecer dados } \\
\text { preliminares sobre o } \\
\text { impacto da COVID-19 nos } \\
\text { serviços de reabilitação } \\
\text { durante os primeiros } \\
\text { estágios de propagação } \\
\text { da pandemia na Europa. }\end{array}$ & $\begin{array}{l}\text { A interrupção das internações para reabilitação, } \\
\text { alta precoce e redução das atividades envolveu } \\
194.800 \text { pacientes internados em dez países. As } \\
\text { atividades ambulatoriais pararam para } 87 \% \text {. Sete } \\
\text { países relataram experiências em reabilitação } \\
\text { para pacientes agudos com COVID-19. }\end{array}$ \\
\hline Lakhani 26 (2020) & Austrália & $\begin{array}{l}\text { Ecológico com } \\
\text { análise espacial }\end{array}$ & $\begin{array}{l}\text { Identificar as áreas de } \\
\text { maior concentração de } \\
\text { idosos com deficiência } \\
\text { e as barreiras de acesso } \\
\text { aos serviços primários } \\
\text { de saúde na cidade de } \\
\text { Melbourne. }\end{array}$ & $\begin{array}{c}\text { Das } 8.910 \text { áreas identificadas, } 2.085 \\
\text { apresentaram nível significativamente alto de } \\
\text { dificuldade para acessar os serviços de saúde } \\
\text { primários e } 807 \text { apresentaram porcentagem } \\
\text { significativamente alta de idosos com deficiência. } \\
\text { A partir desse método, pode-se definir regiões } \\
\text { para ações prioritárias em situações de } \\
\text { emergência pública como a COVID-19. }\end{array}$ \\
\hline
\end{tabular}


Quadro 2

Descrição dos documentos selecionados da literatura cinzenta e síntese dos resultados.

\begin{tabular}{|c|c|c|c|c|}
\hline Estudo (ano) & País & Tipo & Objetivo & Principais achados \\
\hline $\begin{array}{l}\text { Humanity \& Inclusion } 37 \\
\text { (2020) }\end{array}$ & Suíça & $\begin{array}{l}\text { Artigo de } \\
\text { opinião }\end{array}$ & $\begin{array}{l}\text { Apontar medidas } \\
\text { cabíveis para reduzir o } \\
\text { impacto da COVID-19 } \\
\text { para as pessoas com } \\
\text { deficiência. }\end{array}$ & $\begin{array}{c}\text { Indica a adoção de uma abordagem baseada } \\
\text { na garantia dos direitos das pessoas com } \\
\text { deficiência, o que inclui participação na } \\
\text { construção das respostas aos impactos da } \\
\text { COVID-19, disponibilização de informação em } \\
\text { formato acessível e apoio aos serviços de saúde e } \\
\text { telerreabilitação. }\end{array}$ \\
\hline $\begin{array}{l}\text { Organização Internacional } \\
\text { do Trabalho et al. } 33 \text { (2020) }\end{array}$ & $\begin{array}{l}\text { Organização } \\
\text { internacional }\end{array}$ & $\begin{array}{l}\text { Documento } \\
\text { institucional }\end{array}$ & $\begin{array}{l}\text { Apresentar elementos } \\
\text { que podem ajudar a } \\
\text { aproveitar ao máximo } \\
\text { a resposta dos } \\
\text { sistemas de proteção } \\
\text { social à COVID-19 para } \\
\text { apoiar pessoas com } \\
\text { deficiência. }\end{array}$ & $\begin{array}{c}\text { Deve-se garantir acesso à informação, incluir } \\
\text { as pessoas com deficiência e familiares em } \\
\text { programas de recuperação financeira, avaliar } \\
\text { necessidade, criar e ampliar suporte e redes de } \\
\text { apoio. }\end{array}$ \\
\hline $\begin{array}{l}\text { Organização Mundial da } \\
\text { Saúde } 2 \text { (2020) }\end{array}$ & $\begin{array}{l}\text { Organização } \\
\text { internacional }\end{array}$ & $\begin{array}{l}\text { Documento } \\
\text { institucional }\end{array}$ & $\begin{array}{l}\text { Apresentar medidas } \\
\text { individuais e } \\
\text { governamentais } \\
\text { para os profissionais } \\
\text { de saúde e para os } \\
\text { prestadores de serviço } \\
\text { sobre como lidar } \\
\text { com pessoas com } \\
\text { deficiência e reduzir o } \\
\text { impacto da pandemia } \\
\text { da COVID-19 sobre } \\
\text { elas. }\end{array}$ & $\begin{array}{l}\text { Deve-se garantir acesso às informações e } \\
\text { aos serviços de saúde e incentivar atividades } \\
\text { remotas, inclusive a telerreabilitação, para evitar } \\
\text { aglomerações. As medidas governamentais devem } \\
\text { ser inclusivas para as pessoas com deficiência e os } \\
\text { prestadores de serviços, além de garantir suporte } \\
\text { em necessidades complexas. }\end{array}$ \\
\hline $\begin{array}{l}\text { Organização Internacional } \\
\text { do Trabalho } 30 \text { (2020) }\end{array}$ & $\begin{array}{l}\text { Organização } \\
\text { internacional }\end{array}$ & $\begin{array}{l}\text { Documento } \\
\text { institucional }\end{array}$ & $\begin{array}{l}\text { Destacar ações } \\
\text { para promoção } \\
\text { da igualdade de } \\
\text { oportunidades e } \\
\text { trabalho decente } \\
\text { às pessoas com } \\
\text { deficiência durante } \\
\text { a pandemia da } \\
\text { COVID-19. }\end{array}$ & $\begin{array}{l}\text { Enfatiza a necessidade de justiça social, inclusão } \\
\text { efetiva, igualdade de oportunidades e trabalho } \\
\text { decente. Sugere-se assegurar o trabalho remoto } \\
\text { e a comunicação acessível e inclusiva, assim } \\
\text { como acesso às informações divulgadas, tendo } \\
\text { as pessoas com deficiência como cocriadores. } \\
\text { Também deve-se proporcionar sistema de } \\
\text { proteção social adequado. }\end{array}$ \\
\hline $\begin{array}{l}\text { Organização das Nações } \\
\text { Unidas }{ }^{3} \text { (2020) }\end{array}$ & $\begin{array}{l}\text { Organização } \\
\text { internacional }\end{array}$ & $\begin{array}{l}\text { Entrevista } \\
\text { com Catalina } \\
\text { Devandas } \\
\text { (especialista da } \\
\text { organização) }\end{array}$ & $\begin{array}{l}\text { Apresentar medidas } \\
\text { de acomodação para } \\
\text { redução dos riscos } \\
\text { de contágio para } \\
\text { enfrentamento da } \\
\text { COVID-19. }\end{array}$ & $\begin{array}{l}\text { Incentivo ao serviço remoto ou licença } \\
\text { remunerada, ajuda financeira adicional e apoio } \\
\text { adequado para a pessoas com deficiência e sua } \\
\text { família. }\end{array}$ \\
\hline
\end{tabular}

(continua) 
Quadro 2 (continuação)

\begin{tabular}{|c|c|c|c|c|}
\hline Estudo (ano) & País & Tipo & Objetivo & Principais achados \\
\hline Ofner et al. 38 (2020) & Canadá & $\begin{array}{l}\text { Artigo de } \\
\text { opinião }\end{array}$ & $\begin{array}{l}\text { Descrever ações de } \\
\text { prevenção individuais } \\
\text { e para os serviços } \\
\text { de saúde durante } \\
\text { o enfrentamento à } \\
\text { COVID-19. }\end{array}$ & $\begin{array}{l}\text { Ações individuais envolvem receber ajuda para } \\
\text { tarefas essenciais e evitar sair de casa, além } \\
\text { de buscar maneiras de proteger, ouvir, apoiar, } \\
\text { adaptar e acomodar. Nos serviços, deve-se garantir } \\
\text { o atendimento das necessidades e a presença } \\
\text { do acompanhante, levando em consideração } \\
\text { as individualidades nos centros de avaliação } \\
\text { da COVID-19, que precisam ser acessíveis e } \\
\text { acolhedores. }\end{array}$ \\
\hline $\begin{array}{l}\text { Escritório do Alto } \\
\text { Comissariado dos Direitos } \\
\text { Humanos, Organização das } \\
\text { Nações Unidas } 31 \text { (2020) }\end{array}$ & $\begin{array}{l}\text { Organização } \\
\text { internacional }\end{array}$ & $\begin{array}{l}\text { Documento } \\
\text { institucional }\end{array}$ & $\begin{array}{l}\text { Refletir sobre } \\
\text { dificuldades } \\
\text { encontradas pelas } \\
\text { pessoas com } \\
\text { deficiência no contexto } \\
\text { da pandemia da } \\
\text { COVID-19 a partir dos } \\
\text { determinantes sociais } \\
\text { da saúde. }\end{array}$ & $\begin{array}{l}\text { Discriminação, dependência, exclusão escolar, } \\
\text { baixa renda, entre outros, estão envolvidos } \\
\text { no maior risco de contágio na pessoas com } \\
\text { deficiência. Deve-se seguir medidas de } \\
\text { distanciamento, mas oferecer informações em } \\
\text { formatos acessíveis e garantir recursos financeiros } \\
\text { e cuidado à saúde de qualidade. }\end{array}$ \\
\hline $\begin{array}{l}\text { Escritório do Alto } \\
\text { Comissariado dos Direitos } \\
\text { Humanos, Organização das } \\
\text { Nações Unidas } 40 \text { (2020) }\end{array}$ & $\begin{array}{l}\text { Organização } \\
\text { internacional }\end{array}$ & Editorial & $\begin{array}{l}\text { Refletir sobre o } \\
\text { envolvimento } \\
\text { do governo no } \\
\text { enfrentamento } \\
\text { da pandemia da } \\
\text { COVID-19 e enfatizar } \\
\text { a aplicação dos } \\
\text { princípios de não } \\
\text { discriminação. }\end{array}$ & $\begin{array}{l}\text { Atribui-se ao governo a responsabilidade pelas } \\
\text { intervenções que salvam vidas. Os princípios de } \\
\text { não discriminação, participação, empoderamento } \\
\text { e responsabilidade precisam ser aplicados a todas } \\
\text { as políticas. Os estados devem adotar medidas } \\
\text { adicionais de proteção social para que seu apoio } \\
\text { chegue àqueles que correm maior risco de serem } \\
\text { desproporcionalmente afetados pela crise. }\end{array}$ \\
\hline $\begin{array}{l}\text { Rede Pan-Africana de } \\
\text { Pessoas com Deficiência } \\
\text { Psicossocial } 34 \text { (2020) }\end{array}$ & $\begin{array}{l}\text { Organização } \\
\text { internacional }\end{array}$ & $\begin{array}{l}\text { Documento } \\
\text { institucional }\end{array}$ & $\begin{array}{l}\text { Apresentar medidas } \\
\text { de proteção às } \\
\text { pessoas com } \\
\text { deficiência psicossocial } \\
\text { para governos locais } \\
\text { e nacionais durante } \\
\text { a pandemia da } \\
\text { COVID-19. }\end{array}$ & $\begin{array}{l}\text { Enfatiza a garantia de acesso à informação e } \\
\text { aos serviços, assim como sua continuidade para } \\
\text { redução de danos. Sugere evitar medidas de } \\
\text { coerção/medicamento que comprometam a } \\
\text { saúde. Devem ser instituídos apoio comunitário } \\
\text { e biopsicossocial, com canais de suporte e de } \\
\text { atendimento para violência doméstica. Inclusão } \\
\text { da pessoas com deficiência nas decisões a serem } \\
\text { tomadas. }\end{array}$ \\
\hline $\begin{array}{l}\text { Fundo das Nações Unidas } \\
\text { para a Infância } 32 \text { (2020) }\end{array}$ & $\begin{array}{l}\text { Organização } \\
\text { internacional }\end{array}$ & $\begin{array}{l}\text { Documento } \\
\text { institucional }\end{array}$ & $\begin{array}{l}\text { Apresentar os } \\
\text { impactos da pandemia } \\
\text { da COVID-19 para } \\
\text { pessoas com } \\
\text { deficiência e medidas } \\
\text { para preveni-los e } \\
\text { superá-los. }\end{array}$ & $\begin{array}{l}\text { Dificuldades no acesso à educação remota, } \\
\text { interrupção de serviços de suporte, } \\
\text { discriminação na oferta de cuidado e barreiras } \\
\text { no acesso à informação aumentam os riscos de } \\
\text { morbimortalidade pela COVID-19. Deve-se garantir } \\
\text { acessibilidade e continuidade nos serviços de } \\
\text { educação e saúde e ações para prevenção de } \\
\text { violência doméstica. }\end{array}$ \\
\hline
\end{tabular}

(continua) 
Quadro 2 (continuação)

\begin{tabular}{|c|c|c|c|c|}
\hline Estudo (ano) & País & Tipo & Objetivo & Principais achados \\
\hline $\begin{array}{l}\text { Organização das Nações } \\
\text { Unidas } 29 \text { (2020) }\end{array}$ & $\begin{array}{l}\text { Organização } \\
\text { internacional }\end{array}$ & $\begin{array}{l}\text { Documento } \\
\text { institucional }\end{array}$ & $\begin{array}{l}\text { Apresentar o impacto } \\
\text { da pandemia da } \\
\text { CovID-19 nas pessoas } \\
\text { com deficiência } \\
\text { com vista na } \\
\text { interseccionalidade } \\
\text { e recomendações de } \\
\text { enfrentamento. }\end{array}$ & $\begin{array}{l}\text { Desigualdades preexistentes, necessidades e } \\
\text { condições de saúde específicas, interrupção de } \\
\text { serviços essenciais, isolamento social e falta de } \\
\text { acessibilidade na informação contribuem para } \\
\text { vulnerabilização das pessoas com deficiência. } \\
\text { Deve-se garantir a continuidade do acesso } \\
\text { a serviços de saúde, educação, seguridade } \\
\text { e proteção social, bem como acessibilidade } \\
\text { nas informações e medidas de prevenção } \\
\text { e representatividade no planejamento de } \\
\text { estratégias. }\end{array}$ \\
\hline $\begin{array}{l}\text { Organização das Nações } \\
\text { Unidas } 36 \text { (2020) }\end{array}$ & $\begin{array}{l}\text { Organização } \\
\text { internacional }\end{array}$ & $\begin{array}{l}\text { Artigo de } \\
\text { opinião }\end{array}$ & $\begin{array}{l}\text { Apresentar o impacto } \\
\text { da pandemia da } \\
\text { CovID-19 a pessoas } \\
\text { com deficiência. }\end{array}$ & $\begin{array}{l}\text { A pandemia está intensificando desigualdades } \\
\text { preexistentes no contexto de pessoas com } \\
\text { deficiência. Medidas adotadas pelos governos } \\
\text { apresentam inúmeras barreiras, gerando exclusão } \\
\text { e aumentando a vulnerabilidade dessa população. } \\
\text { As pessoas com deficiência devem fazer parte } \\
\text { do processo de construção das medidas de } \\
\text { enfrentamento para incluir suas necessidades. } \\
\text { Basear-se nos direitos das pessoas com deficiência } \\
\text { é investir numa sociedade mais inclusiva e } \\
\text { acessível. }\end{array}$ \\
\hline $\begin{array}{l}\text { Serviço Nacional de Pessoas } \\
\text { com Deficiência } 35 \text { (2020) }\end{array}$ & Chile & $\begin{array}{l}\text { Documento } \\
\text { institucional }\end{array}$ & $\begin{array}{l}\text { Fornecer diretrizes } \\
\text { para comunicação } \\
\text { e atendimento } \\
\text { de pessoas com } \\
\text { deficiência durante } \\
\text { a pandemia da } \\
\text { COVID-19. }\end{array}$ & $\begin{array}{l}\text { O profissional deve realizar uma prática inclusiva, } \\
\text { garantindo a participação do usuário no processo } \\
\text { de assistência e acesso a medicamentos, } \\
\text { tratamentos e equipamentos essenciais à vida. } \\
\text { Deve-se respeitar e prezar pela autonomia da } \\
\text { pessoas com deficiência, dirigindo-se quando } \\
\text { possível ao indivíduo e não ao acompanhante. } \\
\text { Deve-se promover a acessibilidade nos ambientes, } \\
\text { informações e diferentes formas de comunicação. }\end{array}$ \\
\hline $\begin{array}{l}\text { Serviço Nacional Chileno de } \\
\text { Incapacidades } 43 \text { (2020) }\end{array}$ & Chile & Protocolo & $\begin{array}{l}\text { Apresentar diretrizes e } \\
\text { ações para residências } \\
\text { de adultos com } \\
\text { deficiência durante } \\
\text { a pandemia da } \\
\text { COVID-19. }\end{array}$ & $\begin{array}{l}\text { Indica a presença de um profissional coordenador } \\
\text { das estratégias de prevenção em articulação } \\
\text { com a atenção primária. É preciso alterar o } \\
\text { funcionamento das residências, de modo a } \\
\text { garantir as medidas de proteção recomendadas } \\
\text { pelas organizações de saúde, mantendo os } \\
\text { residentes informados sobre elas, bem como } \\
\text { afastar trabalhador e isolar residente que } \\
\text { apresentar sintomatologia. }\end{array}$ \\
\hline $\begin{array}{l}\text { Secretaria Nacional dos } \\
\text { Direitos da Pessoa com } \\
\text { Deficiência, Ministério da } \\
\text { Mulher, da Família e dos } \\
\text { Direitos Humanos } 10 \text { (2020) }\end{array}$ & Brasil & Cartilha & $\begin{array}{c}\text { Divulgar } \\
\text { recomendações } \\
\text { sobre a COVID-19 } \\
\text { aos profissionais que } \\
\text { atendem as pessoas } \\
\text { com deficiência e com } \\
\text { doenças raras. }\end{array}$ & $\begin{array}{l}\text { Recomenda investigar agravos relacionados a } \\
\text { deficiência que são potenciais fatores de risco; } \\
\text { trabalhar com prevenção e manutenção da } \\
\text { assistência de forma remota ou atendimento } \\
\text { domiciliar; orientar acompanhantes e cuidadores } \\
\text { sobre medidas de proteção; e prezar pela garantia } \\
\text { dos direitos humanos associados ao conhecimento } \\
\text { científico em todas as ações desenvolvidas. }\end{array}$ \\
\hline
\end{tabular}

(continua) 


\begin{tabular}{|c|c|c|c|c|}
\hline Estudo (ano) & País & Tipo & Objetivo & Principais achados \\
\hline $\begin{array}{l}\text { Ministério Público do } \\
\text { Trabalho } 42\end{array}$ & Brasil & Nota técnica & $\begin{array}{l}\text { Apresentar as } \\
\text { diretrizes de } \\
\text { proteção nas } \\
\text { relações trabalhistas } \\
\text { de pessoas com } \\
\text { deficiência. }\end{array}$ & $\begin{array}{l}\text { A medidas de flexibilização no trabalho devem } \\
\text { garantir o direito de realizar atividades laborais de } \\
\text { modo remoto e, quando não for possível, dispensa } \\
\text { das obrigações com remuneração garantida ou } \\
\text { flexibilização da jornada com custeio de transporte } \\
\text { particular, sendo assegurado que tais medidas não } \\
\text { implicarão em redução da remuneração. Adotar } \\
\text { medidas de prevenção e proteção. Quando houver } \\
\text { diagnóstico da COVID-19, devem ser afastados. }\end{array}$ \\
\hline $\begin{array}{l}\text { Departamento de Saúde } \\
\text { e Serviços Humanos dos } \\
\text { Estados Unidos } 41 \text { (2020) }\end{array}$ & Estados Unidos & Boletim & $\begin{array}{l}\text { Orientar prestadores } \\
\text { de serviço quanto a } \\
\text { ações guiadas pela } \\
\text { observância aos } \\
\text { direitos civis dos } \\
\text { diferentes segmentos } \\
\text { da população. }\end{array}$ & $\begin{array}{l}\text { O planejamento para enfrentamento de } \\
\text { emergências deve atender às necessidades } \\
\text { de pessoas com deficiências em suas mais } \\
\text { diversas condições, garantindo acessibilidade } \\
\text { na informação por meio do uso de todas as } \\
\text { ferramentas disponíveis para uma comunicação } \\
\text { eficaz, estocando itens que ajudarão as pessoas a } \\
\text { manter a independência e respeitando pedidos de } \\
\text { ajustes no tratamento devido à religião, bem como } \\
\text { acesso às práticas relativas à fé. }\end{array}$ \\
\hline $\begin{array}{l}\text { Organização das Nações } \\
\text { Unidas } 39 \text { (2020) }\end{array}$ & $\begin{array}{l}\text { Organização } \\
\text { internacional }\end{array}$ & Reportagem & $\begin{array}{l}\text { Informar sobre o } \\
\text { plano de resposta a } \\
\text { emergências para a } \\
\text { COVID-19 do Comitê } \\
\text { Principal de Proteção à } \\
\text { Saúde da Austrália e o } \\
\text { impacto para pessoas } \\
\text { com deficiência. }\end{array}$ & $\begin{array}{c}\text { A vulnerabilidade de pessoas com deficiência } \\
\text { diante da pandemia é produto da interação de } \\
\text { fatores biológicos com barreiras atitudinais, } \\
\text { ambientais e institucionais. O plano emergencial } \\
\text { não incluiu necessidades de pessoas com } \\
\text { deficiência e trabalhadores de apoio à deficiência. } \\
\text { Isso mobilizou uma defesa significativa dessa } \\
\text { comunidade, levando o governo australiano a } \\
\text { criar um grupo consultivo para que pessoas com } \\
\text { deficiência opinem e desenvolvam um plano } \\
\text { específico para o contexto da CovID-19. É essencial } \\
\text { que os países adotem uma abordagem dos direitos } \\
\text { humanos para construir sociedades equitativas. }\end{array}$ \\
\hline
\end{tabular}

$\cos 10,41,42,43$. Desses, a maioria foi publicada por organizações internacionais, ao exemplo da Organização das Nações Unidas (ONU) (Quadro 2). Os resultados foram sistematizados em três categorias temáticas que agrupam os principais achados a serem desenvolvidos na discussão: vulnerabilidades das pessoas com deficiência diante da pandemia; direitos das pessoas com deficiência nesse contexto; e medidas de proteção e acesso à informação sobre COVID-19 voltadas para pessoas com deficiência.

\section{Discussão}

O surgimento da pandemia da COVID-19, o alto índice de hospitalização e a crise em sistemas de saúde ao redor do mundo trouxeram à tona a discussão sobre priorização da oferta dos serviços e equipamentos de saúde, além da necessidade de medidas de prevenção e proteção, incluindo distanciamento social. A literatura revisada aponta que, num contexto de emergência em saúde pública, 
Figura 1

Fluxograma detalhando o processo de identificação, seleção, elegibilidade e inclusão dos textos revisados.

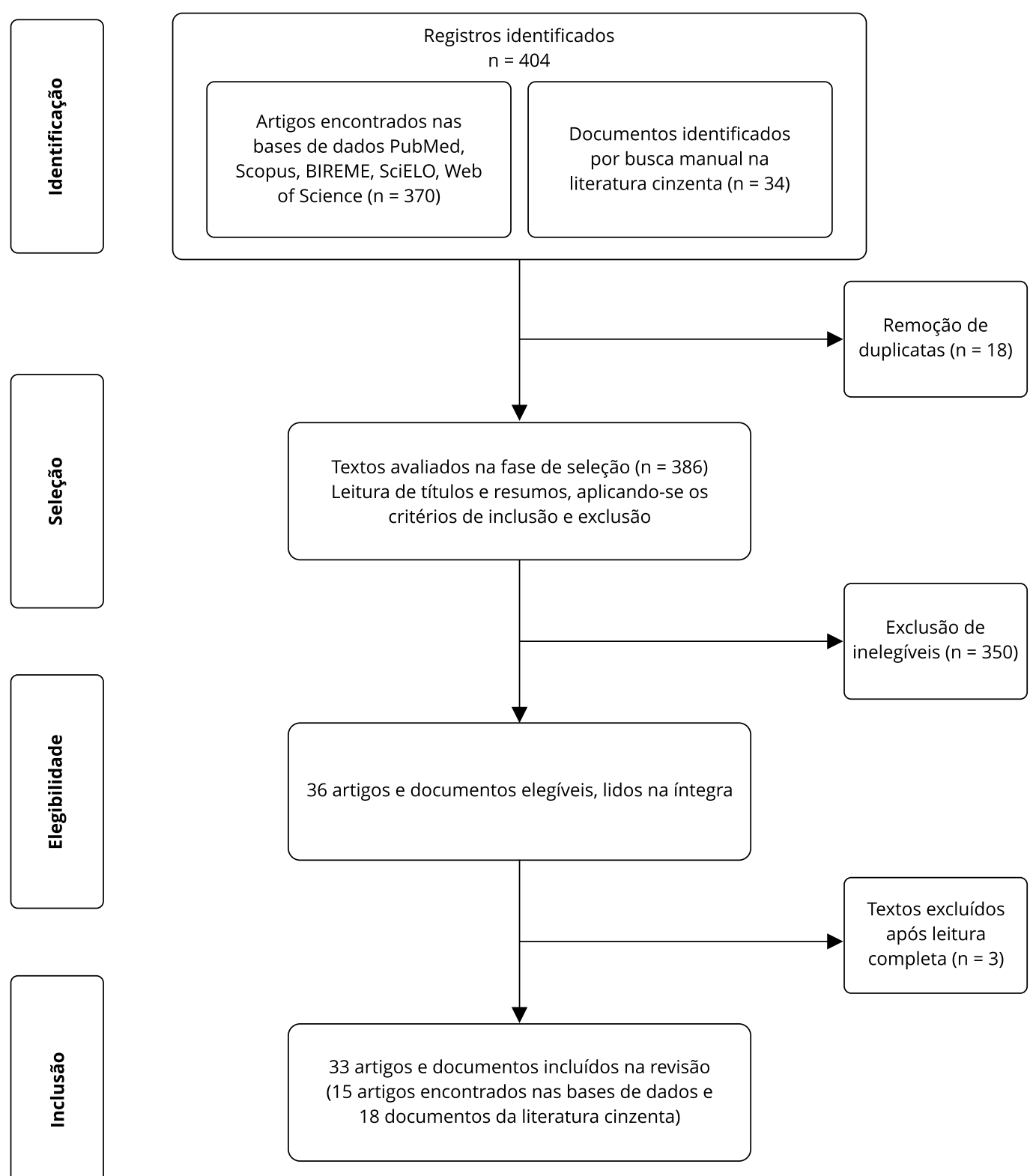

comunidades historicamente marginalizadas, como as pessoas com deficiência, podem estar mais vulneráveis, sofrer mais privações e discriminação nos planos de triagem de atendimento, além de preconceitos e estigmas que influenciam nas tomadas de decisão na assistência em saúde e intensificam desigualdades preexistentes, tornando esses grupos mais suscetíveis ao adoecimento e à desproteção social 18,29,36,39. 


\section{Vulnerabilidades das pessoas com deficiência diante da pandemia da COVID-19}

As pessoas com deficiência não são inerentemente vulneráveis. Barreiras atitudinais, ambientais e institucionais resultam em níveis mais altos de vulnerabilidade, fazendo com que esse grupo, que apresenta condições de saúde subjacentes, esteja sob maior risco de contrair a COVID-19 e/ou ter quadros mais graves da doença 39. Aqui, parte-se da perspectiva de vulnerabilidade social e de saúde não determinística ou natural, associada a situações e contextos individuais e coletivos. Portanto, tal condição de vulnerabilidade pode ser transformada a partir do apoio da sociedade, instituições e governos 44 .

O modelo social da deficiência, modelo teórico explicativo que busca superar o modelo biomédico, amplia a compreensão sobre a vulnerabilidade de pessoas com deficiência, deslocando o olhar das diferenças relacionadas ao corpo para as estruturas sociais. Ele se fundamenta numa nova compreensão sobre os impedimentos vivenciados pelas pessoas com deficiência, não limitada aos diagnósticos de anormalidade ou patologia e aos espaços domésticos. Ou seja, o tema da deficiência deve ser discutido como parte da vida pública, uma questão de justiça, diretamente relacionada às questões sociais 45 .

Um dos efeitos sociais e de saúde relacionados à pandemia, que coloca as pessoas com deficiência em situação de vulnerabilidade, é o agravamento de perdas econômicas e ausência de mecanismos de proteção social, que pode levar as pessoas com deficiência a ter até quatro vezes mais chances de adoecer no contexto da pandemia 20,37. Mesmo países que ratificaram a convenção da ONU sobre os direitos das pessoas com deficiência tiveram dificuldades para incorporar as necessidades desse grupo, em meio a uma emergência em saúde pública, revelando a fragilidade da implementação das diretrizes da convenção 27,39 .

As pessoas com deficiência podem apresentar um risco maior de contrair COVID-19 devido a fatores como barreiras à implementação de algumas medidas básicas de higiene; dificuldade no acesso a direitos básicos como água, moradia, alimentação ou serviços de saúde; e mais dificuldades em manter o distanciamento social, devido ao apoio adicional de que necessitam ou porque estão institucionalizadas 2,15,29,37. A falta de renda representa uma dificuldade desproporcional para as pessoas com deficiência e suas famílias, que normalmente enfrentam custos e despesas extras relacionados à deficiência. Essa população tem menor acesso ao emprego e, quando empregadas, são mais propensas a estar no setor informal, com maior instabilidade e menos acesso à seguridade social. Além disso, têm menos probabilidade de concluir a educação e maior chance de serem excluídas da escolaridade 15.

Fatores como idade, condições crônicas subjacentes, natureza de algumas deficiências e obstáculos para acessar serviços de saúde exacerbam os problemas de saúde dessa população, como restrição na função respiratória ou do sistema imunológico, doenças cardíacas ou diabetes, podendo colocar esse grupo em maior risco de, ao adoecer pela COVID-19, progredir para uma infecção mais grave e apresentar maior mortalidade 2,32,33,38.

As pessoas com deficiência estão super-representadas entre a população carcerária, institucionalizada e sem-teto, e correm um risco maior de infecção devido às condições precárias de vida nesses ambientes. Durante a pandemia, aumentou o número de pessoas com deficiência vivendo em abrigos de emergência e assentamentos informais 29,31. Além disso, esses grupos, quando institucionalizados, aumentam a dependência de outras pessoas na vida comunitária e a necessidade de contato com pessoas que vivem fora dessas instituições. A mortalidade entre pessoas com deficiência tem sido maior do que entre as pessoas sem deficiência em instalações de reabilitação, instituições estaduais, incluindo prisões, casas de grupo e casas de repouso 21. A interação desse grupo com vários prestadores de assistência, suporte e amigos gera um risco aumentado de contrair COVID-19, pelo aumento da exposição, enquanto as restrições de visitantes e pessoas de apoio em instituições pode deteriorar as condições de cuidados e gerar sofrimento mental 38 .

Pessoas com deficiência psicossocial, que geralmente vivem em unidades psiquiátricas e prisões, podem ter um risco maior de contrair COVID-19, o que as impede de exercer o distanciamento social. Além disso, esses espaços são insalubres e sem o suporte de saúde ideal ${ }^{34}$. Crianças com transtorno do espectro autista e outros grupos de pessoas com deficiência intelectual podem enfrentar dificuldades maiores com o distanciamento social e o confinamento, gerando estresse e outros problemas de saúde mental. Os efeitos da vida sedentária causados pelo isolamento e as desigualdades no acesso 
aos ambientes de aprendizagem online também devem ser parte das preocupações para evitar maior impacto da pandemia na vida das pessoas com deficiência 28,31 .

As medidas de saúde adotadas por alguns governos para o enfrentamento da pandemia podem gerar inúmeras barreiras que intensificam a exclusão e aumentam a vulnerabilidade dessa população, como, por exemplo, medidas severas de proteção e prevenção como distanciamento social; paralisação do transporte, comércio, circulação logística e serviços; decisões de racionamento de saúde baseadas em critérios discriminatórios; ou a ausência de acessibilidade nos conteúdos produzidos para informar a população sobre a pandemia. Se essas medidas não levarem em conta as necessidades das pessoas com deficiência, desfechos indesejáveis, como o óbito de pessoas com deficiência relatados na China, podem ser consequência das políticas governamentais 27,36.

Medidas tomadas para impedir a propagação do vírus podem não permitir que os mais vulneráveis, marginalizados e em risco, se protejam com eficiência. A resposta a outras necessidades de saúde, doenças crônicas, condições subjacentes de saúde, tão essenciais para algumas pessoas com deficiência, pode se tornar impossível durante a pandemia devido a restrições no acesso aos serviços de saúde e diminuição do apoio social, gerando sentimentos negativos, medo, sintomas de ansiedade e depressão 2,22,33,37,38.

Dados de um estudo observacional apontaram que, em dez países da Europa, foi relatada a interrupção das internações para reabilitação, alta precoce e redução das atividades assistenciais, chegando à interrupção de $87 \%$ das atividades ambulatoriais na Itália, na Bélgica e no Reino Unido, com estimativa de milhões de pessoas com deficiência atingidos 25 . Esse grupo pode também sofrer dificuldades no acesso a serviços de saúde por serem desqualificados para receber cuidados prioritários durante a pandemia, aumentando ainda mais desigualdades existentes 37.

As despesas relacionadas com a deficiência podem aumentar durante a pandemia em função do impacto da crise e causar danos aos sistemas de apoio, sobrecarregando pessoas com deficiência e suas famílias. Por isso, é necessário proporcionar a proteção social adequada para cobrir esses custos e diminuir as desigualdades. As medidas de diminuição da propagação do novo coronavírus devem vir articuladas com aumento da resposta às necessidades de saúde e apoio à cadeia de suprimentos, fornecendo insumos e serviços de saúde adequados e garantindo a manutenção de serviços vitais de saúde para pessoas com deficiência 30,37. A avaliação das necessidades das pessoas com deficiência durante a pandemia deve considerar a existência de grupos mais vulneráveis (crianças, mulheres, idosos, pessoas com altos níveis de dependência), para que sejam implementados benefícios sociais, suporte de renda, aumento de benefícios por incapacidade, transferência de renda a todas as pessoas com deficiência, independentemente do status de trabalho, durante a pandemia 23,33.

\section{Direitos das pessoas com deficiência no contexto da pandemia da COVID-19}

Considerando que a maioria dos países são signatários da Convenção Internacional sobre os Direitos das Pessoas com Deficiência e que esse importante documento visa promover, proteger e assegurar o exercício pleno e equitativo de todos os direitos humanos e liberdades fundamentais por todas as pessoas com deficiência, promovendo o respeito pela sua dignidade inerente 46 , o contexto da pandemia da COVID-19 trouxe inúmeros desafios para o cumprimento dos objetivos dessa convenção no mundo.

Uma das razões de consulta ética mais frequentes no período de pandemia é a recusa informada de tratamento para pessoas com deficiência, o que tem resultado em processos por critérios de exclusão de atendimento considerados discriminatórios, movidos contra alguns governos 19. A atuação de grupos em defesa dos direitos das pessoas com deficiência no controle e fiscalização das medidas adotadas pelos governos e garantia de que direitos sejam atendidos nos planos operacionais, nesse contexto, torna-se fundamental 14,37.

A garantia dos direitos humanos, o respeito à dignidade e aos direitos das pessoas com deficiência e a diminuição das desigualdades são o caminho para fornecer acesso imparcial e inclusivo aos serviços de saúde e à proteção social. A ideia de que todos têm direito a intervenções que salvam vidas, que populações vulneráveis precisam de políticas equitativas específicas e que essas políticas são responsabilidade dos governos precisa ser fortalecida nesse contexto de pandemia 28,37,40,47. A escassez de recursos ou o uso de planos de seguro públicos ou privados nunca devem ser justificativa para 
discriminar grupos vulneráveis. Esforços multilaterais combinados e o princípio da solidariedade são caminhos para superação das desigualdades e melhoria da capacidade de resposta governamental e da sociedade durante a pandemia 40,47 .

\section{Participação efetiva das pessoas com deficiência na construção de respostas eficazes à pandemia da COVID-19}

A luta das pessoas com deficiência e organizações que as representam compõe a história de defesa e conquista de ações afirmativas, mudanças nas legislações e instituição de políticas de proteção a esse grupo de pessoas 48. Assim, também durante a pandemia, é fundamental garantir que as pessoas com deficiência e suas organizações representativas tenham participação e responsabilidades efetivas em todos os estágios da elaboração de estratégias de enfrentamento da pandemia, monitorando todas as fases de resposta e recuperação da pandemia, de modo a identificar e garantir uma abordagem inclusiva, baseada em direitos, que compreenda os impactos sofridos durante emergências de saúde $16,29,36,37,40$

Sistemas de atendimento inclusivos garantem que todos se beneficiem e geram um impacto positivo no bem-estar das pessoas com deficiência, suas famílias e comunidades. A experiência do governo australiano, que inicialmente elaborou um plano de resposta à emergência sanitária que não levava em consideração as necessidades das pessoas com deficiência, provocou uma resposta significativa da comunidade de pessoas com deficiência. O governo australiano acabou criando um grupo consultivo em abril de 2020, incluindo essa população, para desenvolver um plano específico para o combate à pandemia da COVID-19 junto a essa comunidade, dois meses após o lançamento do plano inicial 16,29. É importante também destacar que pessoas com deficiência já possuíam experiência na adaptação dos espaços e tempo de trabalho e isso pode ser usado como referência no contexto atual, utilizando as soluções e infraestruturas conquistadas por pessoas com deficiência que possam ser disseminadas durante a pandemia 21.

Para garantir acessibilidade, disponibilidade e qualidade dos serviços, os governos devem construir melhores estratégias de planejamento e intervenção que incluam profissionais de saúde do cuidado direto, em formatos de atendimento domiciliar e baseados na comunidade, medidas de proteção que priorizem que pessoas com deficiência recebam o apoio, com segurança, de cuidadores e familiares. Planos de resposta às emergências em saúde devem buscar atender o conjunto da população, mas não podem desconsiderar as especificidades de populações vulneráveis. Ao direcionar políticas para pessoas com deficiência, devem observar os segmentos ainda mais vulnerabilizados desse grupo, como pessoas institucionalizadas, mulheres e imigrantes 7,17,24,29,39.

A coleta de informações desagregadas por sexo, idade e incapacidade e a construção de evidências sobre o impacto da pandemia e das medidas de prevenção sobre os diferentes grupos populacionais possibilitam ter uma conta factual do impacto da pandemia, possibilitando respostas equitativas que levem em consideração a interseccionalidade dos fatores de exclusão 32,37. A produção de informações públicas, atualizadas, detalhadas e não discriminatórias, faz com que as pessoas com deficiência possam se beneficiar da equidade e da justiça na alocação de recursos e ser apoiadas efetivamente em planos nacionais e internacionais contra crises como a pandemia da COVID-19 23,33.

As pessoas devem receber rapidamente treinamento de conscientização sobre os direitos e diversas necessidades das pessoas com deficiência, para manter a dignidade desse grupo, salvaguardá-lo da discriminação e prevenir desigualdades na prestação de cuidados. Garantir estoque de itens que ajudarão as pessoas com deficiência a manter a independência, como aparelhos auditivos, baterias, bengalas e dispositivos auxiliares; disponibilizar salas reservadas para acolhimento de pessoas com deficiência, levando em consideração as múltiplas necessidades dessa população; atender todos os segmentos da comunidade; e tomar decisões no sentido de oferecer uma oportunidade igualitária de se beneficiar dos esforços de enfrentamento da pandemia são medidas que podem mitigar as desigualdades em saúde aprofundadas durante a pandemia 28,38,41.

Políticas que enfrentem a pandemia, com acomodações que incluam a diversidade das pessoas com deficiência, diminuam a estigmatização, estimulem a empatia e solidariedade e contribuam para uma resposta efetiva à emergência são fundamentais. Conexões entre ciência e ações políticas têm que ser fortalecidas para a busca de soluções de longo prazo no enfrentamento da pandemia e suas conse- 
quências. Investir nos direitos das pessoas com deficiência é investir numa sociedade mais inclusiva e acessível, permitindo, assim, alcançar os objetivos de desenvolvimento sustentável 22,35,36,41.

\section{Medidas de proteção e acesso à informação voltadas para pessoas com deficiência no contexto da pandemia}

A pandemia da COVID-19, tanto pela circulação de um vírus de alta transmissibilidade e aumento da pressão nos sistemas e serviços de saúde 27, quanto pelas medidas de enfrentamento, como o distanciamento social, acentuou a vulnerabilidade preexistente das pessoas com deficiência 20, impactando diretamente no aumento da desproteção social e isolamento dessa população. Portanto, são necessárias medidas de proteção social, incluindo saúde, educação e acesso à informação voltadas a essa população nos âmbitos governamentais, institucionais e individuais (família e cuidadores).

\section{Governos}

$\mathrm{O}$ acesso à saúde, incluindo às tecnologias assistivas 32 , a medicamentos e equipamentos de saúde 26,37; a continuidade dos serviços de redução de danos e inclusão de pessoas com deficiência 3; e o acesso a informações confiáveis e acessíveis precisam ser garantidos nas discussões e tomadas de decisão sobre as medidas de prevenção da COVID-19 e atenção às pessoas com deficiência durante a pandemia 2,22,27,34,37. Centros de avaliação da COVID-19 devem ser acessíveis e acolhedores, incluindo acessibilidade física, e levar em consideração as individualidades das pessoas com deficiência 27. A necessidade de produção de respostas às barreiras de acesso e comunicação durante a pandemia incluem o chamado a uma mudança de narrativa a partir da inclusão das pessoas com deficiência como coparticipantes das respostas à pandemia, como defensores e usuários, e não como vítimas 30 .

Os serviços de reabilitação são essenciais e, por isso, os governos precisam incluir profissionais da reabilitação e outros tipos de cuidados domiciliares, ou baseados na comunidade, nos planos de garantia de equipamentos de proteção individual e de treinamentos para a nova realidade, além da capacitação e instrumentalização para a telereabilitação 24. No Brasil, o Sistema Único de Saúde (SUS) prevê a coexistência de pontos de atenção da Rede de Cuidados às Pessoas com Deficiência 49 nos diferentes níveis de atenção, o que tende a potencializar a manutenção das ações de reabilitação, desde que sejam garantidas a proteção à saúde e a capacitação dos trabalhadores. Embora algumas iniciativas de orientações governamentais 10,47 tenham acontecido, além de oportunidades de formação de profissionais do SUS para o cuidado 50, pouco se sabe sobre a situação de saúde das pessoas com deficiência no contexto brasileiro durante a pandemia.

A produção de informações também inclui a análise da situação de saúde das pessoas com deficiência, através de investigações epidemiológicas 17 . Nesse sentido, um dos estudos descreve a estrutura de método espacial para identificar áreas prioritárias para serviços de cuidados paliativos em tempos de crise, para organizar a oferta de serviços para o apoio à saúde das pessoas mais vulneráveis 26 . Tal estratégia poderia ser utilizada por organizações governamentais para a descentralização e distribuição de serviços de saúde ou proteção social, baseadas na equidade do acesso. Porém o que se observou foi uma lacuna de estudos observacionais sobre situação de saúde das pessoas com deficiência durante a pandemia. Vale ressaltar que as investigações, quando realizadas, devem preservar a privacidade e o anonimato das informações referentes às pessoas com deficiência, respeitando os princípios da ética na pesquisa e atenção à saúde 35 .

Governos também devem garantir participação de órgãos regionais, a exemplo de conselhos municipais e organizações de pessoas com deficiência 21 e familiares, em uma atuação coordenada, monitorando diretrizes de ação e orçamento que abordem especificamente as medidas de prevenção à COVID-19, de modo a garantir máxima disseminação de informações, remover barreiras financeiras de acesso a cuidados de saúde 30,32 e incluir instituições residenciais 47 .

Ainda em relação às informações sobre a COVID-19, estas devem ser compartilhadas em formatos acessíveis, em tempo hábil e com o uso de tecnologias acessíveis à comunicação pública, evitando estereotipar mensagens e imagens e garantindo que a proteção seja um elemento central dos planos estratégicos dos países para a resposta à pandemia 21,37. A comunicação deve incorporar a necessidade de mensagens de emergência, em linguagem simples, nos idiomas predominantes nas áreas afetadas, em vários formatos (áudio, letras grandes e legendas) ${ }^{41}$. 
No que se refere ao trabalho e renda, com a necessidade de medidas de distanciamento social e quarentena, precisam ser garantidas orientações quanto a práticas de autocuidado para identificação de potenciais sinais e sintomas, formas de prevenção com acessibilidade na comunicação, trabalho remoto sem redução na remuneração e afastamento do trabalho no caso de sintomas para trabalhadores com deficiência, bem como cuidadores familiares 21,42. As estratégias de garantia de distanciamento social e trabalho remoto devem considerar licenças remuneradas, antecipação de férias individuais, concessão de férias coletivas ou aproveitamento e antecipação de feriados e banco de horas. A Organização Internacional do Trabalho (OIT) prevê, inclusive, a necessidade de assistência pessoal às pessoas com deficiência para realização de suas atividades laborais 30. Para os trabalhadores da economia informal, chama-se atenção da necessidade de garantia de benefícios assistenciais 33. Essas recomendações, em relação à flexibilização do trabalho das pessoas com deficiência, devem ser direcionadas às empresas, órgãos públicos, empregadores, pessoas físicas, sindicatos patronais e profissionais de todos os setores econômicos ou entidades sem fins lucrativos 42 .

\section{Instituições e profissionais responsáveis pelo cuidado (saúde e social)}

A implementação do distanciamento social exacerbou as restrições de acesso a serviços de saúde e sociais às pessoas com deficiência, incluindo ao próprio diagnóstico da COVID-19, especialmente às que residem em instituições 31,39. Segundo a ONU, nos dois primeiros meses da pandemia, as pessoas com deficiência tiveram pouca ou nenhuma informação acessível sobre os sintomas da COVID-19, medidas de prevenção e de distanciamento social, especialmente na necessidade de manutenção do contato com cuidadores profissionais 39 para a manutenção de serviços vitais, como alimentação, higiene e cuidados em saúde 37.

No que se refere às instituições de educação, foram necessárias medidas de ensino remoto, mesmo considerando que poderiam não favorecer as pessoas com deficiência devido à falta de apoio e acessibilidade a softwares ${ }^{29}$. A interrupção de serviços como escola, centros comunitários e terapias tende a impactar negativamente na saúde e bem-estar geral das pessoas com deficiência, podendo levar a uma regressão do desenvolvimento 38 . O desafio que se coloca é garantir acesso a esses serviços, mantendo o desenvolvimento positivo das pessoas com deficiência em contextos sociais tão diversos, superando barreiras ambientais e sociais.

Nas instituições de saúde, a garantia de acesso, continuidade e inclusão em serviços de cuidado também devem considerar atribuições dos profissionais de saúde e incluir possibilidades de teleatendimento 2,15 e telereabilitação 17 . É preciso garantir que todos os procedimentos que serão executados, mesmo os conhecidos pela maioria da população, sejam explicados em múltiplos formatos que garantam que as pessoas com deficiência tenham entendimento e autonomia nas escolhas 35 . Além disso, é necessário o reforço nas orientações aos familiares quanto às medidas de prevenção 47 . Os serviços de emergência e hospitalização precisam ser adaptados, resolvendo barreiras ambientais e ampliando o acesso, considerando todos os tipos de deficiência 35 . Os serviços também precisam garantir o direito a acompanhantes e que as informações sejam fornecidas de maneira funcional, multilíngue e culturalmente apropriada 38 .

Os serviços de reabilitação são essenciais e a telerreabilitação é uma estratégia para garantir a continuidade do cuidado em saúde, mas depende de capacitação dos profissionais e colaboração entre eles, de garantia de recursos e infraestrutura, e de treinamento de usuários e familiares. A suspensão desses serviços pode resultar em aumento de incapacidades para aqueles que demandam cuidado continuado 24 .

Barreiras no acesso a serviços e informações, bem como o não cumprimento de medidas de prevenção nos espaços responsáveis pelo cuidado às pessoas com deficiência, discriminação e circunstâncias de abuso e violências diversas, podem afetar mais mulheres, pessoas idosas e outras minorias sociais. Abordagens personalizadas, com orientações sobre o gerenciamento dos riscos e das consequências da COVID-19, podem ser estratégicas no cuidado a pessoas mais vulneráveis com deficiência, ao exemplo dos idosos, evitando deslocamentos desnecessários para serviços de saúde 26. As informações precisam ser compartilhadas em formato acessível, adaptada às diferentes necessidades das pessoas com deficiência, incorporando estratégias de avaliação do nível de compreensão 35 . 
Também por isso, medidas contra a discriminação e violências envolvem a garantia do acesso à informação e serviços de qualidade 34 e de serviços de assistência às vítimas inclusivos e acessíveis por meio de redes voluntárias de aconselhamento e apoio remoto ${ }^{29}$. Nesse contexto, um dos documentos refere a necessidade de apoio comunitário e psicossocial por ferramentas online que considerem medidas de flexibilização da quarentena, de forma segura e curta, para aquelas com maiores dificuldades de manter o confinamento, além da oferta de canais de suporte e atendimento para violência doméstica 34 .

As instituições residenciais para pessoas com deficiência também devem investir em medidas de reforço de higiene, utilização de equipamentos de proteção individual e coletiva, distanciamento social, testagem de trabalhadores e residentes 17,39,43 e afastamento de sintomáticos 43 . A telerreabilitação também pode ser estratégica nessas instituições, diminuindo a circulação de pessoas 17, mas considerando os diferentes acessos a tecnologias e à Internet das pessoas 24 . Outro aspecto importante é o risco de aumento do sofrimento mental devido aos desafios impostos pela pandemia, que demanda estratégias comportamentais e medidas adaptativas dos serviços de suporte e profissionais engajados na continuidade dos cuidados às pessoas com deficiência 18,38. Segundo relatório da ONU, a falta de informações acessíveis em alguns países - por exemplo, por não incluir a língua de sinais - gerou medo, ansiedade e confusão ${ }^{39}$, demandando que serviços de saúde mental utilizassem telemedicina em linguagem acessível e levassem em consideração a garantia de acesso à Internet e outros meios de comunicação para populações vulneráveis 22 .

\section{Família e cuidadores das pessoas com deficiência no contexto da pandemia da COVID-19}

O acompanhamento das pessoas com deficiência por uma pessoa de apoio - familiar, amigo ou cuidador profissional - deve ser um direito, tendo em vista a necessidade de algumas pessoas de apoio adicional para tarefas essenciais 2,15,35,38. No entanto, as pessoas com deficiência que dependem de apoio podem estar em uma situação difícil, pois elas ou seus cuidadores podem adoecer ou ser expostos ao risco de contaminação ${ }^{30}$. Nesse sentido, é fundamental incluir família e cuidadores das pessoas com deficiência nas políticas públicas.

Os profissionais de saúde devem estar atentos aos familiares e cuidadores das pessoas com deficiência, pois estes são importantes para manutenção do cuidado e redução do risco de infecção e dos impactos das mudanças ambientais 18. Assim, devem prepará-los para o caso do adoecimento pela COVID-19 e cuidar da sua saúde mental e física 2, além de orientá-los sobre os cuidados de prevenção 17.

Para crianças com autismo, recomenda-se incentivar práticas de atividades físicas, para mantê-las fisicamente ativas e calmas em casa, contribuindo para que outros membros da família obtenham ganhos psicológicos 28 .

Em locais onde o acesso a cuidados de saúde é difícil ou os sistemas de saúde estão sobrecarregados devido à pandemia, é fundamental programas de telessaúde visando as habilidades dos cuidadores familiares 26. No Irã, foram fornecidos materiais educacionais para pessoas com deficiências específicas e suas famílias/cuidadores e instituído um sistema com informações das necessidades médicas e de reabilitação da pessoas com deficiência para que, caso o cuidador principal adoeça, um cuidador substituto acesse 23 .

Os cuidadores e familiares devem estar atentos a sinais e sintomas antes de qualquer interação com as pessoas com deficiência, pois seu adoecimento poderá resultar em quebra do suporte doméstico. Em caso de infecção do cuidador ou das pessoas com deficiência pela COVID-19, outros contatos (familiares, cuidadores, amigos) devem ser informados imediatamente. Os cuidadores também têm o papel de proteger, ouvir, apoiar, adaptar e ofertar acomodações adequadas às pessoas com deficiência $15,18,38$.

A ONU aponta a necessidade dos familiares e cuidadores terem acomodações adequadas para fornecer apoio às pessoas com deficiência durante esse período. Pensar medidas razoáveis de acomodação pode reduzir o risco de contaminação das pessoas com deficiência 39. Outra questão importante é a garantia do transporte ou deslocamentos seguros a essas pessoas, uma vez que inadequações no transporte público podem dificultar ou até mesmo impedir o apoio de amigos e familiares, a exemplo das experiências de lockdown 27. 


\section{Considerações finais}

As pessoas com deficiência foram reconhecidas como grupo de risco para a COVID-19 por organizações internacionais e nacionais de saúde, além de organizações de luta pelos direitos das pessoas com deficiência. Porém, é importante destacar que esse grupo não é inerentemente vulnerável. As barreiras atitudinais, ambientais e institucionais resultam em níveis mais altos de vulnerabilidade, fazendo com que as pessoas com deficiência sejam historicamente marginalizadas, tenham dificuldades de acesso e sofram mais privações e discriminação nos planos de triagem dos serviços, além de preconceitos e estigmas que influenciam a tomada de decisão na atenção em saúde, intensificando desigualdades preexistentes.

Populações vulneráveis, como as pessoas com deficiência, precisam de políticas específicas que garantam acesso a direitos e equidade no acesso a políticas de proteção social também no contexto da pandemia da COVID-19. A formulação e a implementação dessas políticas são de responsabilidade dos governos e devem garantir a participação das pessoas com deficiência e suas organizações representativas, desde a elaboração das propostas até o monitoramento dos planos de resposta e recuperação da pandemia. Além dos governos, a garantia dos direitos e proteção da vida das pessoas com deficiência também devem ser objeto de ação das instituições da sociedade civil, através de medidas de fortalecimento de vínculos comunitários, familiares, de acesso a cuidadores, e garantia de informações adequadas para maior autonomia dessas pessoas no autocuidado.

As evidências apontam um atraso generalizado dos governos na construção de planos de enfrentamento à COVID-19 que levem em consideração as necessidades das pessoas com deficiência e sua baixa participação na formulação desses planos. Os achados dialogam com a realidade brasileira, onde o Governo Federal apresentou um plano de enfrentamento da pandemia para pessoas com deficiência quase quatro meses após o início da pandemia 51 . As adaptações sociais propostas durante a pandemia da COVID-19 já eram parte das reivindicações das pessoas com deficiência sobre como fazer a sociedade funcionar de forma a acolher as diversidades humanas. A garantia de trabalho remoto, adaptações nos locais de trabalho, oferta de serviços domiciliares, ampliação de políticas sociais, formas inclusivas de comunicação, qualificação das informações e prestação de serviços, no cotidiano das sociedades no pós-pandemia, promovem o exercício pleno e equitativo de todos os direitos humanos e liberdades fundamentais das pessoas com deficiência e de outras populações vulneráveis.

Apesar da grande quantidade de documentos sistematizados neste estudo, pouco se sabe sobre a realidade das pessoas com deficiência durante a pandemia. Assim, são necessárias investigações sobre os efeitos da pandemia nas pessoas com deficiência, para que políticas, programas e serviços sejam dimensionados e as medidas de prevenção, controle e proteção sejam orientadas segundo necessidades e demandas de saúde dessa população. A escassez de estudos primários sobre a situação de saúde das pessoas com deficiência durante a pandemia da COVID-19 e sobre os efeitos das políticas governamentais pode comprometer respostas mais efetivas para a garantia de direitos e equidade no cuidado.

Outras revisões conduzidas em 2020 buscaram compreender o impacto da pandemia da COVID-19 em diferentes grupos de pessoas com deficiência. Uma recente revisão descreve impactos nas atividades de vida diária, como diminuição no acesso aos cuidados de saúde, mudanças nos hábitos sociais e de estilo de vida, mudanças de humor e diminuição dos níveis de atividade física ${ }^{52}$. Trauma e estresse dentro da comunidade de pessoas com deficiência, incluindo preocupações sobre o racionamento e incapacidade nos cuidados de saúde, isolamento e as mortes e doenças de entes queridos e membros da comunidade, foram descritos como relacionadas à pandemia 53 , além da ampliação dos problemas e das barreiras enfrentadas pelas pessoas com deficiência que sofrem violência interpessoal. Essas questões incluem dependência do agressor para cuidado e assistência, barreiras para denunciar o abuso e buscar ajuda, medo de retaliação e outras consequências negativas 54 .

Os planos de emergência, desenvolvidos com foco no combate à disseminação do vírus e a ampliação dos serviços emergenciais, muitas vezes deixam de considerar questões específicas das pessoas com deficiência e não levam em consideração todas as áreas de atenção. As estratégias de reabilitação devem incluir os pacientes afetados pela COVID-19 e aqueles com outras condições potencialmente incapacitantes 55. Crianças com deficiência são desproporcionalmente impactadas pela COVID-19 e pela resposta de contenção. Assim, seus cuidadores buscam se adaptar a fatores de estresse crescentes, 
como a falta de acesso às terapias necessárias, a suprimentos médicos e a cuidados de enfermagem. Antes da pandemia, essas famílias já eram marginalizadas e isso só piorou no contexto atual 56 . Nosso estudo dialoga com essas revisões na medida em que explicita o aumento das barreiras para as pessoas com deficiência durante a pandemia da COVID-19. Nossa opção por uma busca ampla, sem recortes de subgrupos, possibilitou a síntese de achados que abordam os impactos da pandemia e a necessidade de políticas para garantir a equidade no cuidado para as pessoas com deficiência.

Dado o volume e a velocidade de publicações sobre a pandemia da COVID-19 no segundo semestre de 2020, nosso estudo apresenta como limitação a síntese de textos do momento inicial da pandemia, e as respostas encontradas podem ter sofrido mudanças à medida que novos estudos foram publicados. Novos estudos devem ser realizados, buscando acompanhar a evolução da situação da saúde das pessoas com deficiência durante a pandemia e as respostas governamentais e institucionais para essa população específica.

Considerando a vulnerabilidade social e econômica das pessoas com deficiência e o risco aumentado para a infecção e óbito por COVID-19, o aumento da produção científica sobre as condições de vida e saúde das pessoas com deficiência são fundamentais para a produção de respostas efetivas no combate aos efeitos dessa pandemia e em futuras emergências sanitárias.

\section{Colaboradores}

J. H. S. Saldanha e M. M. C. Almeida participaram da concepção do artigo, análise e interpretação dos dados, redação do artigo, revisão crítica do conteúdo intelectual e aprovaram a versão final a ser publicada. A. P. M. Pereira colaborou na concepção do artigo, coleta, análise e interpretação dos dados, redação do artigo, revisão crítica do conteúdo intelectual e aprovou a versão final a ser publicada. A. O. C. Santos, B. S. Miranda, H. K. S. Carvalho, L. C. Nascimento, M. S. Amaral, M. S. Macedo e M. Catrini participaram da coleta, análise e interpretação dos dados, redação do artigo e aprovaram a versão final a ser publicada.

\section{Informações adicionais}

ORCID: Jorge Henrique Santos Saldanha (00000001-9883-6962); Ana Paula Medeiros Pereira (0000-0003-3670-8222); Amanda Oliveira Costa dos Santos (0000-0001-7493-5608); Beatriz Santos Miranda (0000-0001-7536-9804); Hercília Kayla Santos de Carvalho (0000-0003-1494-665X); Lilia Campos Nascimento (0000-0002-4347-7031); Mariana Santos Amaral (0000-0001-5665-6947); Mariana Silva Macedo (0000-0001-5834-6846); Melissa Catrini (0000-0002-2947-3157); Milena Maria Cordeiro de Almeida (0000-0001-80654298).

\section{Referências}

1. World Health Organization. Disability and health. https://www.who.int/en/news-room/ fact-sheets/detail/disability-and-health (acessado em 18/Ago/2020).

2. World Health Organization. Disability considerations during the COVID-19 outbreak. https://apps.who.int/iris/bitstream/ handle/10665/332015/WHO-2019-nCovDisability-2020.1-eng.pdf (acessado em 05/ Mai/2020).

3. United Nations Organization. COVID-19: who is protecting the people with disabilities? https://www.ohchr.org/EN/NewsEvents/ Pages/DisplayNews.aspx? NewsID = 25725 (acessado em 25/Mai/2020).

4. Hurst R. The international disability rights movement and the ICF. Disabil Rehabil 2003; 25:572-6.

5. Santos WR. Assistência social e deficiência no Brasil: o reflexo do debate internacional dos direitos das pessoas com deficiência. Serviço Social em Revista 2010; 13:80-101.

6. Diniz D. Modelo social da deficiência: a crítica feminista. LetrasLivres 2003; 28:1-8.

7. Armitage R, Nellums LB. The COVID-19 response must be disability inclusive. Lancet 2020; 5:E257.

8. Instituto Brasileiro de Geografia e Estatística. Nota técnica 01/2018 - Releitura dos dados de pessoas com deficiência no Censo Demográfico 2010 à luz das recomendações do Grupo de Washington. Rio de Janeiro: Instituto Brasileiro de Geografia e Estatística; 2018. 
9. World Health Organization. WHO DirectorGeneral's opening remarks at the media briefing on COVID-19 - 11 March 2020. https://www.who.int/dg/speeches/detail/ who-director-general-s-opening-remarksat-the-media-briefing-on-COVID-19---11march-2020 (acessado em 18/Ago/2020).

10. Secretaria Nacional dos Direitos a Pessoa com Deficiência, Ministério da Mulher, da Família e dos Direitos Humanos. Cartilha pessoas com deficiência e com doenças raras e a COVID-19. https://sway.office.com/ tDuFxzFRhn1s8GGi?ref=Link (acessado em 18/Mai/2020).

11. Arksey H, O’Malley L. Scoping studies: towards a methodological framework. Int J Soc Res Methodol 2005; 8:19-32.

12. Peters MD, Godfrey CM, Khalil H, McInerney P, Parker D, Soares CB. Guidance for conducting systematic scoping reviews. Int J Evid Based Healthc 2015; 13:141-6.

13. Vidal EIO, Fukushima FB. A arte e a ciência de escrever um artigo científico de revisão. Cad Saúde Pública 2021; 37:e00063121.

14. Thomas J, Harden A. Methods for the thematic synthesis of qualitative research in systematic reviews BMC Med Res Methodol 2008; 8:45.

15. Organização Pan-Americana da Saúde. Considerações sobre pessoas com deficiência durante o surto da COVID-19. https://iris.paho. org/handle/10665.2/52063 (acessado em 20/ $\mathrm{Mai} / 2020$ ).

16. Schiariti V. The human rights of children with disabilities during health emergencies: the challenge of COVID-19. Dev Med Child Neurol 2020; 62:661.

17. Safta-Zecheria L. Challenges posed by COVID-19 to the health of people with disabilities living in residential care facilities in Romania. Disabil Soc 2020; 35:837-43.

18. Courtenay K. COVID-19: challenges for people with intellectual. BMJ 2020; 369:m1609.

19. Mukherjee D. Experiencing community in a COVID surge. Hastings Cent Rep 2020; 50:10-1.

20. Pineda VS, Corburn J. Disability, urban health equity, and the coronavirus pandemic: promoting cities for all. J Urban Health 2020; 97:336-41.

21. Shew A. Let COVID-19 expand awareness of disability tech. Nature 2020; 581:9.

22. Vieira CM, Franco OH, Restrepo CG, Abel T. COVID-19: the forgotten priorities of the pandemic. Maturitas 2020; 136:38-41.

23. Jalali M, Shahabi S, Lankarani KB, Kamali M, Mojgano P. COVID-19 and disabled people: perspectives from Iran. Disabil Soc 2020; 35:844-7.

24. Bettger JP, Thoumi A, Marquevich V, Groote W, Battistella LR, Imamura M, et al. COVID-19: maintaining essential rehabilitation services across the care continuum. BMJ Glob Health 2020; 5:e002670.
25. Negrini S, Grabljevec K, Boldrini P, Kiekens C, Moslavac S, Zampolini M, et al. Up to 2.2 million people experiencing disability suffer collateral damage each day of COVID-19 lockdown in Europe. Eur J Phys Rehabil Med 2020; 56:361-5.

26. Lakhani A. Which Melbourne Metropolitan areas are vulnerable to COVID-19 based on age, disability, and access to health services? Using spatial analysis to identify service gaps and inform delivery. J Pain Symptom Manage 2020; 60:41-4.

27. Qi F, Hu l. Including people with disability in the COVID-19 outbreak emergency preparedness and response in China. Disabil Soc 2020; 35:848-53.

28. Yarımkaya E, Esentürk OK. Promoting physical activity for children with autism spectrum disorders during coronavirus outbreak: benefits, strategies, and examples. International Journal of Developmental Disabilities 2020; 66. https://www.tandfonline.com/doi/fu 11/10.1080/20473869.2020.1756115.

29. United Nations. A disability-inclusive response to COVID-19. Washington DC: United Nations; 2020.

30. Organização Internacional do Trabalho. Ninguém ficará para trás, nem agora, nem nunca. Pessoas com deficiência na resposta ao COVID-19. https://www.ilo.org/wcmsp5/ groups/public/---ed_emp/---ifp_skills/docu ments/publication/wcms_741590.pdf (acessado em 25/Abr/2020).

31. Office of the High Commission of the Human Rights, United Nations. COVID-19 and the rights of persons with disabilities: guidance. https://www.ohchr.org/Documents/Issues/ Disability/COVID-19_and_The_Rights_of_ Persons_with_Disabilities.pdf (accessado em 24/Abr/2020).

32. United Nations Children's Fund. COVID-19 response: considerations for children and adults with disabilities. https://www.unicef. org/disabilities/files/COVID-19_response_ considerations_for_people_with_disabili ties_190320.pdf (acessado em 10/Mai/2020).

33. International Labour Organization; United Nations Children's Fund; International Disability Alliance. Disability inclusive social protection response to COVID-19 crisis. https:// www.ilo.org/global/topics/disability-andwork/WCMS_742140/lang--en/index.htm (acessado em 03/Jun/2020).

34. Pan-African Network of Persons with Psychosocial Disabilities. COVID-19 and persons with psychosocial disabilities. Cape Town: Pan-African Network of Persons with Psychosocial Disabilities; 2020.

35. Ministério de Desarrolo Social y Família. Recomendaciones para la atención de personas con discapacidad en el contexto de la pandemia por COVID-19. Santiago: Ministério de Desarrolo Social y Família; 2020. 
36. United Nations. We have a unique opportunity to design and implement more inclusive and accessible societies. Washington DC: United Nations; 2020.

37. Humanity \& Inclusion. A principled and inclusive response to COVID-19, focused on the most vulnerable. https://www.icvanet work.org/system/files/versions/HI\%20Mes sages\%20on\%20COVID 19\%20Policy\%20Pa per\%2015042020\%20ENG_0.pdf (acessado em 10/Mai/2020).

38. Ofner M, Salvadori M, Pucchio A, Chung Y-E, House A; PHAC COVID-19 Clinical Issues Task Group. COVID-19 and people with disabilities in Canada. https://www.canada. $\mathrm{ca} /$ en/public-health/services/diseases/2019. novel-coronavirus-infection/guidance-docu ments/people-with-disabilities.html (acessado em 28/Mai/2020).

39. United Nations. Months in fear, anxiety and confusion: the life of people with disabilities in COVID-19. Washington DC: United Nations; 2020.

40. Office of the High Commission of the Human Rights, United Nations. No exceptions with COVID-19: "Everyone has the right to life-saving interventions" - UN experts say. https://www.ohchr.org/EN/NewsEvents/ Pages/DisplayNews.aspx?NewsID=25746\&La ngID=E\&fbclid=IwAR1vFZDTrmlWSQXRq5 BMJF3144OrKv9HRQevSO_SH1mqOEJXcX DM4KqUHM4 (acessado em 24/Jun/2020).

41. U.S Department of Health and Human Services. Bulletin: civil rights, HIPAA, and the coronavirus disease 2019 (COVID-19). https:// www.hhs.gov/sites/default/files/ocr-bulle tin-3-28-20.pdf (acessado em 15/Abr/2020).

42. Ministério Público do Trabalho. Nota Técnica Conjunta no 07/2020, de 28 de março de 2020. Nota técnica para a atuação do Ministério Público do Trabalho em face das medidas governamentais de contenção da pandemia da doença infecciosa (COVID 19) para trabalhadoras e trabalhadores com deficiência. http://sinicesp. org.br/materias/2020/nota-mpt.pdf (acessado em 10/Mai/2020).

43. Ministerio de Desarrollo Social y Familia. Protocolo de residencias para la prevencíon y atención del COVID-19 en residenciales para adultos con discapacidad. Santiago: Ministerio de Desarrollo Social y Familia; 2020.

44. Carmo ME, Guizardi FC. O conceito de vulnerabilidade e seus sentidos para as políticas públicas de saúde e assistência social. Cad Saúde Pública 2018; 34:e00101417.

45. Diniz D, Barbosa L, Santos WR. Deficiência, direitos humanos e justiça. Sur. Revista Internacional de Direitos Humanos 2009; 6:64-77.

46. United Nations. Convention on the rights of persons with disabilities (CRPD). http://www. un.org/disabilities/documents/natl/portugal-c. doc (acessado em 11/Set/2020).
47. Secretaria Nacional dos Direitos a Pessoa com Deficiência, Ministério da Mulher, da Família e dos Direitos Humanos. Recomendações aos profissionais que atendem as pessoas com deficiência e com doenças raras - coronavírus. https://bibliotecadigital.mdh.gov.br/jspui/ handle/192/1156 (acessado em 18/Mai/2020).

48. Santos WR. Pessoas com deficiência: nossa maior minoria. Physis (Rio J.) 2008; 18:501-19.

49. Ministério da Saúde. Portaria no 793, de 24 de abril de 2012. Institui a Rede de Cuidados à Pessoa com Deficiência no âmbito do Sistema Único de Saúde. Diário Oficial da União 2012; 25 abr.

50. Paranaguá C. Ministério da Saúde e UNA-SUS lançam cinco vídeos sobre Covid-19 com foco nas pessoas com deficiência. https://www.unasus.gov.br/noticia/ministerio-da-saude-e-unasus-lancam-cinco-videos-sobre-covid-19com-foco-nas-pessoas-com-deficiencia (acessado em $25 /$ Set/2020).

51. Secretaria Nacional dos Direitos a Pessoa com Deficiência, Ministério da Mulher, da Família e dos Direitos Humanos. Governo Federal lança plano para diminuir impacto da pandemia na vida de pessoas com deficiência. https://www. gov.br/mdh/pt-br/assuntos/noticias/2020-2/ julho/governo-federal-lanca-plano-paradiminuir-impacto-da-pandemia-na-vida-depessoas-com-deficiencia (acessado em 30/ Set/2020).

52. Lebrasseur A, Fortin-Bédard N, Lettre J, Bussières EL, Best $\mathrm{K}$, Boucher $\mathrm{N}$, et al. Impact of COVID-19 on people with physical disabilities: a rapid review. Disabil Health J 2021; 14:101014.

53. Lund EM, Forber-Pratt AJ, Wilson C, Mona LR. The COVID-19 pandemic, stress, and trauma in the disability community: a call to action. Rehabil Psychol 2020; 65:313-22.

54. Lund EM. Interpersonal violence against people with disabilities: additional concerns and considerations in the COVID-19 pandemic. Rehabil Psychol 2020; 65:199-205.

55. Avellanet M, Boada-Pladellorens A, PagesBolibar E. Rehabilitación en época de confinamiento. Rehabilitación (Madr., Ed. impr.) 2020; 54:269-275.

56. Houtrow A, Harris D, Molinero A, Levin-Decanini T, Robichaud C. Children with disabilities in the United States and the COVID-19 pandemic. J Pediatr Rehabil Med 2020; 13:415-24. 


\section{Abstract}

This is a scoping review of the PubMed, Scopus, BIREME, SciELO, and Web of Science databases, including publications from December 2019 to May 2020 with the objective of identifying and systematizing the literature on the status of persons with disabilities in the initial months of the COVID-19 pandemic. The review aimed to search for original peer-reviewed articles published in indexed journals, in addition to the specialized gray literature. We reviewed 386 texts and included 33 articles and documents in the study. The review's results pointed to three thematic categories that reflect the main discussions on the theme in the literature: vulnerabilities of persons with disabilities during the pandemic; rights of persons with disabilities in this context; and protective measures and access to information on COVID-19 for persons with disabilities. In the context of the public health emergency, historically marginalized communities such as persons with disabilities run the risk of feeling more vulnerable, suffering deprivations, discrimination in screening plans for care, and prejudices and stigmas that influence decision-making in healthcare and exacerbate preexisting inequalities, making this group more susceptible to illness and lack of social protection. Although persons with disabilities have been acknowledged as a risk group for COVID-19, governments have been slow to develop plans to fight COVID-19 for this population. Few studies have attempted to understand the effects of the COVID-19 pandemic on persons with disabilities, especially in the sense of implementing measures in prevention, control, and protection that guarantee equity in care.

Disabled Persons; Coronavirus Infections; COVID-19

\section{Resumen}

Se trata de una revisión de alcance, realizada en las bases de datos PubMed, Scopus, BIREME, SciELO y Web os Science, incluyendo publicaciones de diciembre de 2019 a mayo de 2020, con el objetivo de identificar y sistematizar la literatura sobre la situación de las personas con discapacidad durante los primeros meses de la pandemia de la COVID-19. La revisión se orientó hacia la búsqueda de artículos originales, publicados en revistas indexadas y revisados por pares, además de literatura gris especializada. Se revisaron 386 textos y se incluyeron en el estudio 33 artículos $y$ documentos. El resultado de la revisión apuntó tres categorías temáticas que reflejan las principales discusiones presentadas en la literatura sobre el tema: vulnerabilidades de las personas con discapacidad ante la pandemia; derechos de las personas con discapacidad en ese contexto; $y$ medidas de protección y acceso a la información sobre COVID-19, dirigidas a las personas con discapacidad. En el contexto de emergencia en salud pública, comunidades históricamente marginalizadas, como las personas con discapacidad, corren el riesgo de que se sientan más vulnerables, sufran privaciones, discriminación en los ámbitos de clasificación de atención, además de que padezcan prejuicios y estigmas que influencian en las tomas de decisión en la asistencia en salud e intensifican desigualdades preexistentes, haciendo este grupo más susceptible a la enfermedad y a la desprotección social. Pese a que las personas con discapacidad hayan sido reconocidas como grupo de riesgo para la COVID-19, hubo un atraso, por parte de los gobiernos, en la construcción de planes de lucha contra la COVID-19 para esta población. Son escasos los estudios para la comprensión de los efectos de la pandemia de la COVID-19 en las personas con discapacidad, especialmente en el sentido de la efectivización de medidas de prevención, control y protección que garanticen la equidad en el cuidado.

Personas con Discapacidad; Infecciones por Coronavirus; COVID-19
Recebido em 10/Out/2020

Versão final reapresentada em 22/Abr/2021

Aprovado em 29/Abr/2021 